\title{
Notable Change in Body Color During Copulation in the Scaly-backed Anole, Anolis notopholis (Squamata: Dactyloidea), from Western Colombia
}

\author{
Iván Camilo Beltrán, Pablo Palacios Rodríguez, Daniel Mejía, and Adolfo Amézquita
}

Grupo de Ecofisiología, Comportamiento y Herpetología, Departamento de Ciencias Biológicas, Universidad de los Andes, Bogotá, Colombia, A.A. 4976 (ic.beltran196@uniandes.edu.co)

Photographs by Pablo Palacios Rodríguez.

$\mathrm{C}$ hanges in lizard coloration have been extensively studied during agonistic interactions (e.g., Greenberg and Noble 1944; Greenberg and Crews 1990; Summers and Greenberg 1994), but rarely in the context of sexual interactions. Herein we report a field observation of mating behavior in Anolis notopholis (Boulenger 1896) (Squamata: Dactyloidae), a mainland species that inhabits the Pacific lowlands of Colombia (Fig. 1). The species occupies the lower strata of the forest associated with herbaceous vegetation (van den Elzen and Schuchmann 1986).

We conducted fieldwork from 30 August to 15 September 2015 in an old growth tropical humid forest (sensu Holdridge 1987) near La Victoria, municipality of Cantón de San Pablo, department of Chocó, Colombia (05³0'37'N, 76052'42.4”W, $264 \mathrm{~m}$ asl). We recorded and photographed copulatory and postcopulatory behavior of $A$. notopholis using a Nikon Coolpix p530 camera. The approximate distance between the observer and the focal animals was about $8 \mathrm{~m}$.

The pair was on the leaf litter. When we first observed the lizards, the male was beside the female, biting her back, and showing dark gray lateral coloration. The female had a similar gray coloration and was exhibiting abrupt lateral head movements (Fig. 2A). About 6 min later, the gray coloration of the male disappeared while the female continued bobbing her head (Fig. 2B). The copulation lasted for approximately $46 \mathrm{~min}$; 5 min before the end, the male recovered his dark coloration while the female intensified her head-bobbing (Fig. $2 \mathrm{C})$. The male then released the female and moved away. Subsequently, for another $10 \mathrm{~min}$, we observed head-bobbing and dewlap extension in the male (Fig. 2D).

In lizards, several hormones are known to control the movement of melanin granules within melanophores, causing contraction or expansion and thereby darkening or lightening the body color (e.g., Cooper and Greenberg 1992). In the observation recorded here, the color of the male $A$. notopholis changed from dark gray to light green in 6 min (Fig. 2A-B). At the end of the copulation, the change from light green to gray took approximately $3 \mathrm{~min}$ (Fig. 2C); however, this change was less intense than that observed at the beginning of copulation.

In the few species for which reports exist, the duration of copulation in Anolis generally ranges from 10 to $30 \mathrm{~min}$ (e.g., Jenssen et al. 1995; Tokarz 1999). Interestingly, copulation of $A$. notopholis described herein took about $46 \mathrm{~min}$. Although this could be a unique and interesting feature of the species, we cannot eliminate the possible disturbance effect of observers on copulation duration. Alternatively, most studies describing copulation of anoles are conducted in the laboratory, and copulations might well last longer in the field (Alfonso et al. 2014). Additional data are necessary to discriminate between these hypotheses.

\section{Literature Cited}

Alfonso, Y.U., V. Holanova., and K.L. Krysko. 2014. Copulation and oviposition in the green-blotched giant anole Anolis smallwoodi (Squamata: Dactyloidea), from southeastern Cuba. Reptiles \& Amphibians 21: 108-115.

Cooper, W.E., Jr. and N. Greenberg. 1992. Reptilian coloration and behavior, pp. 298-422. In: C. Gans and D. Crews (eds.), Biology of the Reptilia. Volume 18, Physiology E. Hormones, Brain, and Behavior. University of Chicago Press, Chicago, Illinois.

Greenberg, N. and D. Crews. 1990. Endocrine and behavioral responses to aggression and social dominance in the green anole lizard, Anolis carolinensis. General and Comparative Endocrinology 77: 246-255.

Greenberg, N. and G. Noble. 1944. Social behavior of the American Chameleon (Anolis carolinensis Voigt). Physiological Zoology 17: 392-439.

Holdridge, L.R. 1987. Ecología Basada en Zonas de Vida. Instituto Interamericano de Cooperación para la Agricultura, San José, Costa Rica. 

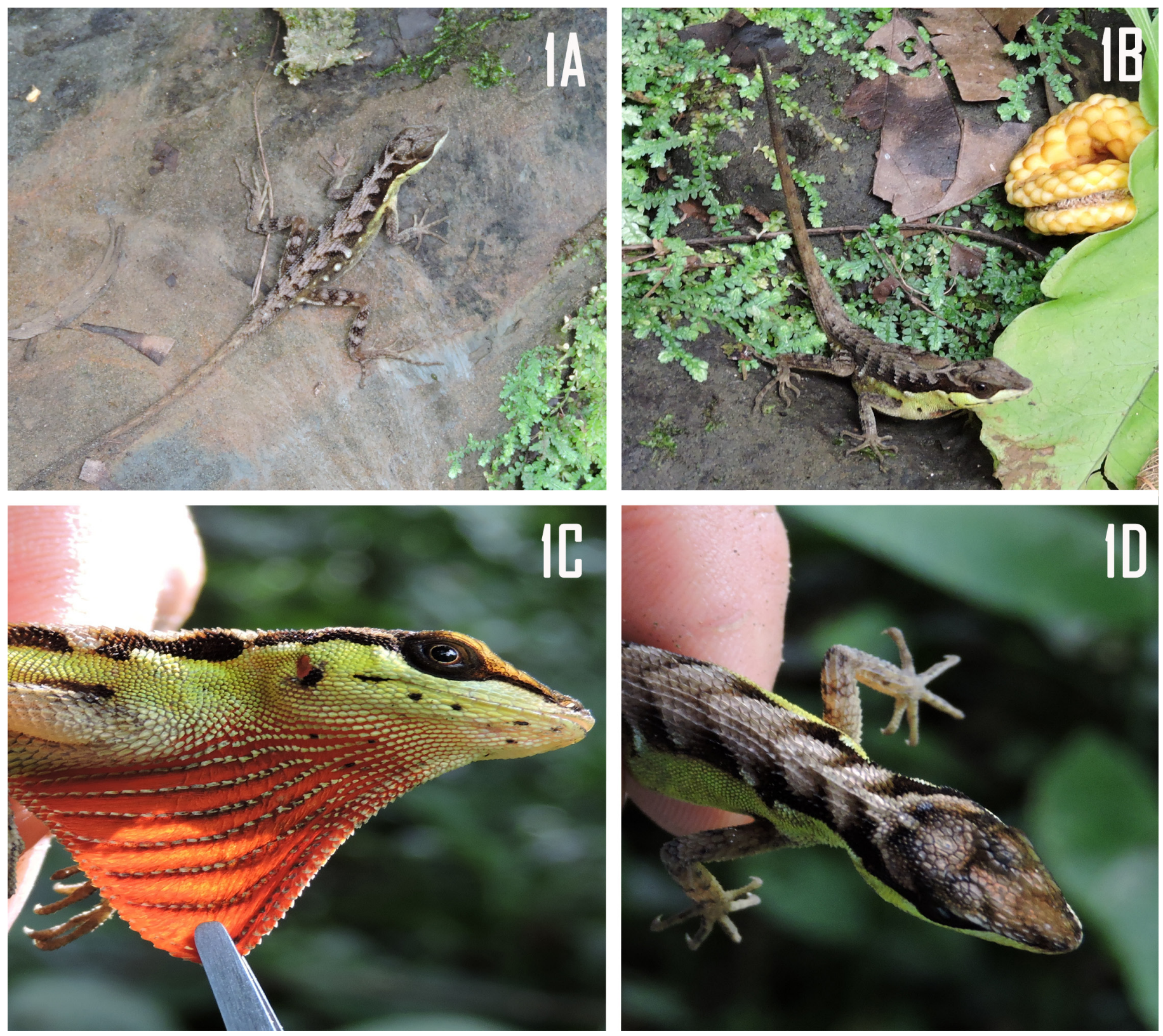

Fig. 1. Scaly-backed Anole (Anolis notopholis) coloration and pattern in a female (A) and a male (B-D).

Jenssen, T., N. Greenberg, and K. Hovde. 1995. Behavioral profile of free-ranging male lizards, Anolis carolinensis, across breeding and post-breeding seasons. Herpetological Monographs 9: 41-62.

Summers, C.H. and N. Greenberg. 1994. Somatic correlates of adrenergic activity during aggression in the lizard, Anolis carolinensis. Hormones and Behavior 28: $29-40$.
Tokarz, R.R. 1999. Relationship between copulation duration and sperm transfer in the lizard Anolis sagrei. Herpetologica 55: 234-241.

van den Elzen, P. and K.L. Schuchmann. 1980. Notes on Anolis notopholis Boulenger, 1896 (Sauria: Iguanidae). Bonner Zoologische Beiträge 31: 319-322. 

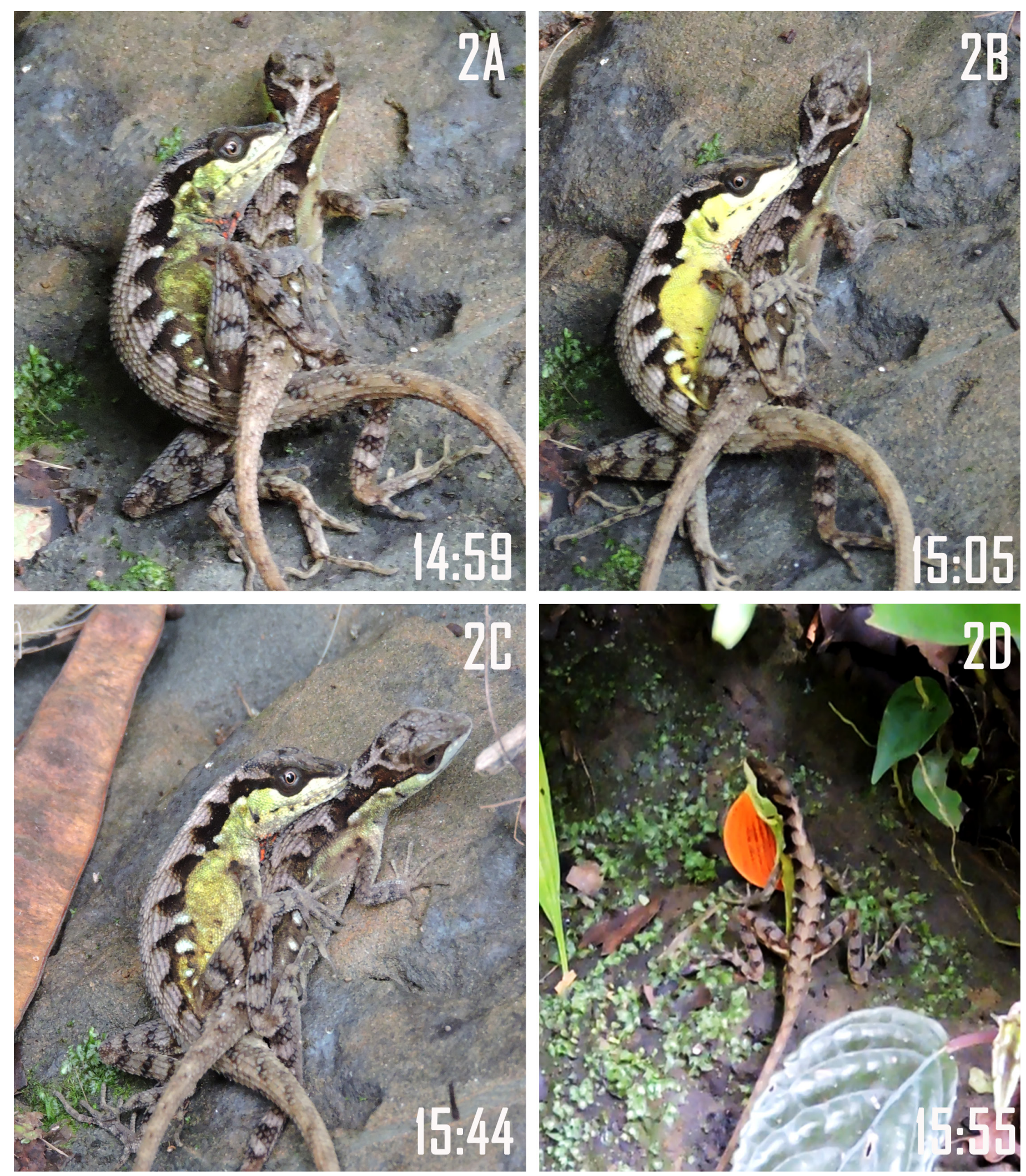

Fig. 2. Copulatory and postcopulatory behavior in Scaly-backed Anoles (Anolis notopholis). Male body coloration is dark at the beginning of the copulation (A) and becomes lighter five minutes later (B). Male coloration becomes dark again a few minutes before the end of copulation (C). After copulation, the male head-bobs and extends his dewlap for several minutes (D). 